https://doi.org/10.31713/m1014

\title{
INFORMATION AND TECHNOLOGICAL ASPECTS OF MINE SURVEYING SUPPORT FOR THE DEVELOPMENT AND CONSERVATION OF SUBSOIL RESOURCES
}

\section{Sayyidkosimov S.S.}

Tashkent State Technical University after named Islam Karimov, Professor, Doctor of Technical Sciences, Professor, Department of Mine survey and Geodesy, Uzbekistan

\section{Raximov Sh.Sh.}

Tashkent State Technical University after named Islam Karimov, $\mathrm{PhD}$, Senior Lecturer, Department of Mine survey and Geodesy,

Uzbekistan

\section{Nizamova A.T.}

Tashkent State Technical University after named Islam Karimov, $\mathrm{PhD}$, Senior Lecturer, Department of Mine survey and Geodesy,

Uzbekistan

\section{Raximova D.B.}

Tashkent State Technical University after named Islam Karimov, $\mathrm{PhD}$, Senior Lecturer, Department of English language, Uzbekistan

\section{A monitoring of career}

The current state of opencast mining, especially deep open pits of OOO «Kharanut», is reached a depth of more than $500 \mathrm{~m}$, requires the organization of systematic instrumental measurements on the sides based on the laid down observation stations, in the form of metal benchmarks, taking into account the developed layouts and observations. This makes it possible to monitor and predict the state of the rock massifs in open pits.

In order to organize geomonitoring of mine surveying observations of the state of open pit slopes, the following is required:

- to take potentially unstable areas based on the analysis of engineering-geological and mining-technical conditions of development for the establishment of observation stations;

- to develop a design for an observation station for deformations of the slopes of the sides of quarries and dumps;

- to set up some benchmarks of observation stations in the quarry; 
- to perform a binding of reference marks with the definition of coordinates $X, Y, Z$ to the nearest points of the reference geodetic network;

- select the positions of the control points of the profile lines;

- to determine the observation point position that is being created the measuring station;

- to carry out systematic control over the invariability of the position of measuring stations using GPS receivers (satellite positioning system);

- instrumental measurements that the benchmarks of the observation station's profile lines;

- the results processing where the instrumental observations and their analysis.

The layout of the observation stations' the profile lines should be selected on the analysis that based on the state edge masses and dump slopes, the modern mining work and the prospects for their further development. To ensure the long service life reference benchmarks, control points and points of measuring stations are proposed to be installed in the form of a permanent reinforced concrete pillar.

In the created monitoring system, it is counselled to monitor the pits and dumps position made by a semi-automatic method. The semi-automatic observation system is based on the production of systematic instrumental surveying and geodetic observations of the displacements and deformations of the working benchmarks that using profile lines an electronic total station and GPS receivers to control the control points and measuring stations position invariability, and in the observation results mathematical processing.

The area is rich with useful mineral deposits: Kharanutskoe coal deposit, Burpalinskoe copper deposit, Golevskoe synnyrites deposit, Katuginskoe cryolite-rare earth-rare metal deposit, Kitemyakhtinskaya gold placer, Olondinskoe lithium deposit, Udokan copper deposit, Chineyskoe iron-titanium-vanadium deposit, Yuzhno -Sulumat iron deposit, etc.

According to the reference terms, the work requires:

- to draw up a work program; 


\section{Creation of digital 3D models of a pit}

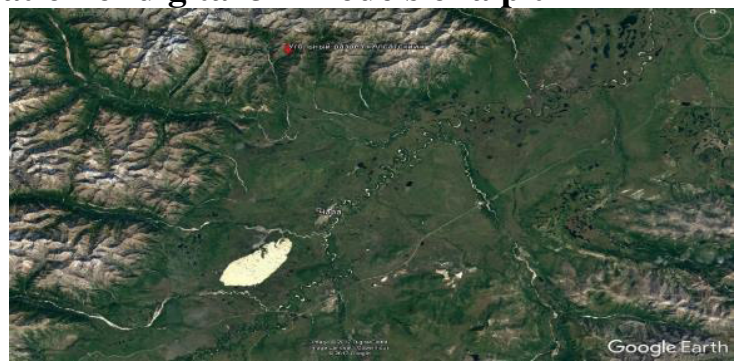

Fig. 1. Diagram of a site layout

- to perform instrumental observations on the Kharanutsky section with a length no more than $2500 \mathrm{~m}$ (Fig.1);

- to create observation stations for performing deformation instrumental observations of the cut sides;

- the work must be performed in accordance with the requirements of the current regulatory and technical documentation.

\section{Reconnaissance of the work area}

Topogeodetic work begins with the auxiliary information collection (diagrams, drawings, map materials) from the responsible Customer's representatives. Based on mine surveying and geodetic maps and plans, ideas were obtained about the nature of the relief, the GGS points location, connected to the work site. Further, the object reconnaissance was carried out.

At this stage, the followings are carried out: the object visual assessment; the object boundaries clarification; the ability to conduct satellite and linear-angular observations.

Based on the results of the work area reconnaissance, conclusions were drawn about the methods of conducting instrumental observations. A work program has been drawn up.

\section{The work methods}

In Static mode, GNSS receivers are installed simultaneously at the initial and determined points for collecting data from all satellites visible in the area. Data collection at points continues during some time, depending on the distance between the receivers, the state of the constellation of satellites, obstacles that affect the collection of data (trees, buildings, mountains, and so on, blocking part of the sky). 
Satellite measurements are performed in a static mode, in sessions the duration of synchronous observations by a pair of receivers at the points that form the spatial vector, not less than thirty minutes. At the same time, special attention was paid to the selection of the most favorable time intervals, when the simultaneous visibility of 10 satellites is ensured.

The static measurement method is the most accurate of any other GNSS survey method. This is mainly due to the increased acquisition time of measurements, and, consequently, the large volume of measurements required for statics (Table 1).

Table 1

Base Station Coordinate Catalog

\begin{tabular}{l|c|c|c}
\hline \multicolumn{1}{c|}{ Names } & $\mathrm{X}$ & $\mathrm{Y}$ & $\mathrm{H}$ \\
\hline БASE BП & 6331944.388 & 570488.701 & 1152.617 \\
\hline BASE Fig.2 & 6334744.245 & 572316.000 & 1563.127 \\
\hline BASE PTK & $\mathbf{6 3 3 4 1 6 9 . 5 2 9}$ & $\mathbf{5 7 2 6 2 9 . 4 9 0}$ & $\mathbf{1 4 7 9 . 7 8 4}$ \\
\hline BASE CM.1 & 6332779.008 & 571886.820 & 1371.588 \\
\hline
\end{tabular}

Geodetic measurements were carried out in the conditional coordinate system and the Baltic 1977 height system.

\section{Topographic survey of the Kharanutsky coal mine}

The survey of the coal mine side was carried out using a RIEGL Z-400I ground-based laser scanning system.

The profit of the ground-based method of laser scanning over tachymetric survey and other types: portable, durable, economical; served by one person; instant three-dimensional visualization; high accuracy; incomparably more complete results; fast data collection; ensuring safety when shooting hard-to-reach and dangerous objects.

The material costs for collecting data and modeling an object that used three-dimensional ground-based laser scanning methods are comparable to traditional survey methods in small areas and objects, and lower in areas of large area or length. Even with comparable survey costs, the completeness and accuracy of the results of terrestrial laser scanning allow that avoiding additional costs at the stages of design, construction and operation of the facility.

Scanning control and transformation of the scanner coordinate system are carried out by the RISCAN PRO and MicroStation software which supplied with the scanner. 


\section{Scanning}

A complex of field work on ground laser scanning was carried out on the work area, consisting of the following types of work:

1. Reconnaissance. Survey work using a ground-based laser scanning system which begins with the collection of auxiliary information (diagrams, drawings, map materials) and the object a reconnaissance is carried out.

2. The creation of a survey rationale determines the necessary coordinates of reference marks (elements of external orientation of the scanner). Reflective marks were temporarily fixed on the ground on special landmarks. The milestones stability was fixed with bipods.

3. Scanning was performed using a RIEGL $Z-400 i$ ground-based laser scanning system. Scanning parameters: $L-950 \mathrm{~m}$, frequency range $150 \mathrm{kHz}: t-24 \mathrm{~min}$, fixation of the last reflection with maximum angular sweeps (Fig. 1-3). For scanning the side of the section, 4 points of the device were required. The placement of scan positions meets the following requirement: from the scanning point, all mine workings and elements to be displayed are clearly visible. Scanning at each station was carried out in 2 stages: performing high density scanning; recognition of reflective marks.

\section{Coordination of reference marks}

To orient the point clouds (obtained during scanning at each scanposition) between themselves in one coordinate system, reflective marks are needed, which are fixed on the ground during scanning.

Coordination of marks was carried out from survey points that using TRIMBLE R8-III GPS receivers

\section{Digital data processing.}

Digital data processing includes the following steps:

1. Transformation (landing) of the point cloud obtained by scanning using the GCP points coordinates files in a certain coordinate system. 


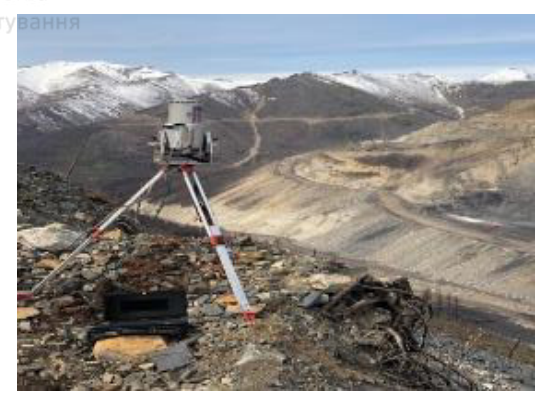

Fig. 2. Installation at the Duty Point of the Scanner RIEGL Z-400I

2. Creation of a digital terrain model. The primary processing of the scan results was performed using the RISCAN PRO and MicroStation software, further processing and construction of the topographic plan were acted with using AutoCAD Civil 3D.

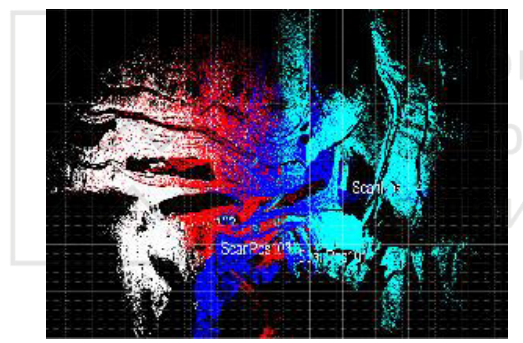

Fig. 3. Location of scan positions (october 2019y)

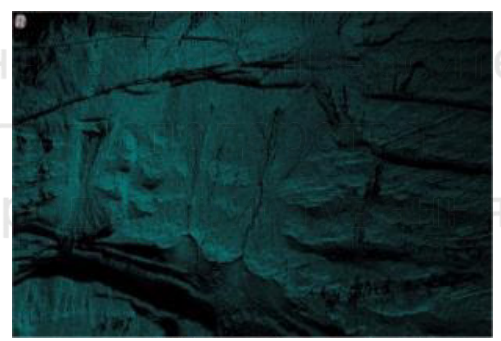

Fig. 4. Thick point cloud after scanning

\section{Field control}

Completeness control that carried out by comparing the material is ready for to transfer with the terrain. In this case, both facts of lack of information and facts of information redundancy are recorded.

The coverage object was controlled by the discharged summary file points of laser reflections from all scans.

Control is necessary in each stage of the work, since the modeling process is quite long and errors can be detected long after till the end of the survey. The accuracy of determining reference marks is also monitored.

\section{Creation of a digital terrain model}

In their essence, the transformed point clouds are already in a digital model with real $3 \mathrm{D}$ coordinates, in the accepted conditional coordinate system of the project, (Fig. 5-9). 
The terrain model that built during post-processing in MicroStation, has an average density of 9 points per $1 \mathrm{~m} 2$. This density allows us to have a full understanding of the actual geometric parameters of relief elements.

Further processing is performed in the AutoCAD Civil 3D environment and the consists in three-dimensional modeling of the characteristic relief contours.

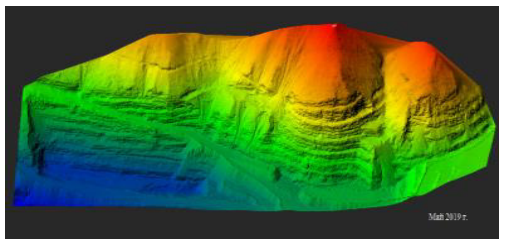

Fig. 5. 3D model of the cut side for May 2019

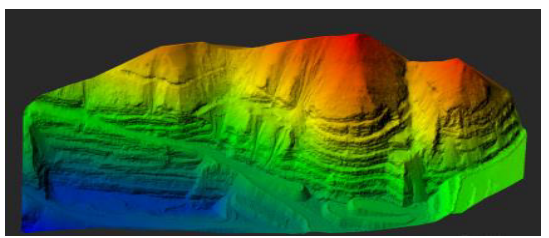

Fig. 6. 3D model of the cut side for October 2019

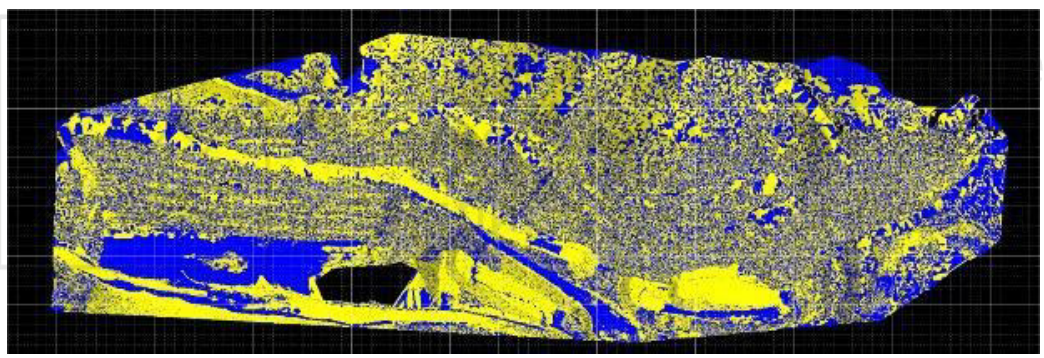

Fig: 7. Comparison of 3D models of the cut flank. View - 2: blue color-May, yellow color - October
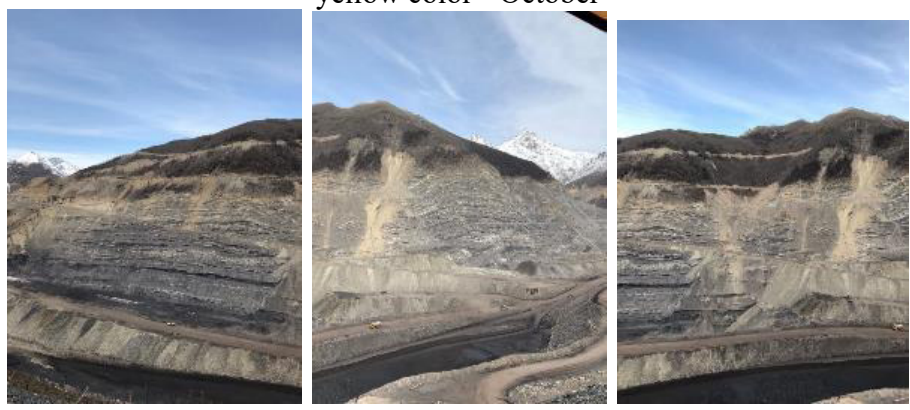

Fig. 8. Photo report of the cut side 

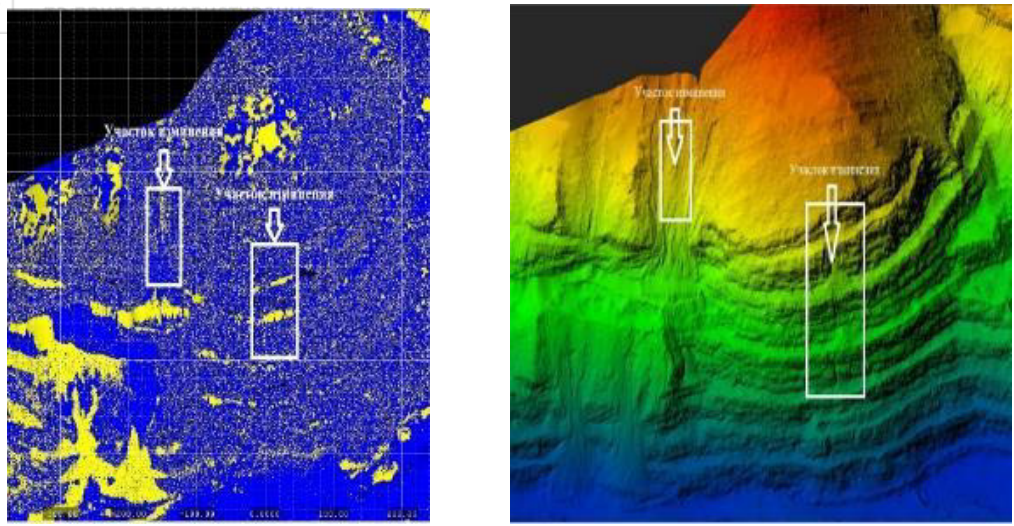

Fig. 9. Section of the Kharanutsky open-cut mine (indicating displacements and deformations)

The comparative analysis that based on the monitoring results was carried out to determine the deformations and displacements of the sides of the Kharanutsky coal mine, according to the data of ground-based laser scanning for various periods, which was carried out in the RISCAN PRO environment (Fig. 4.10). Digital elevation models (DEM) were built based on two observation cycles. DEM according to observations of the first cycle is plotted in blue, the second cycle - in yellow. The comparison results show the places where deformations and displacements are detected.
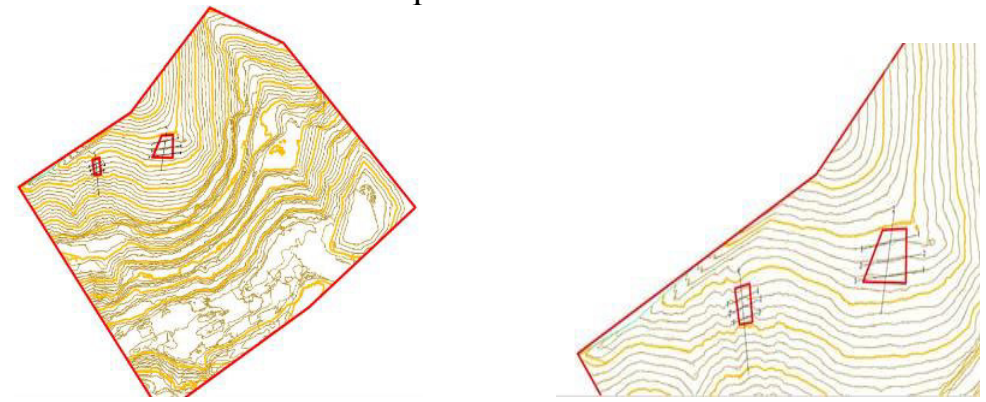

Fig. 10. A plot of debris recorded based on the results of 2 observation cycles

There are the graphs below that built according to the data in Fig. 9, which shows the dynamics of the changes in the state of the 
working side of the section for two cycles of observations and the displacements identified (red - 1 cycle, green - 2 cycle) (Fig. 11-18).

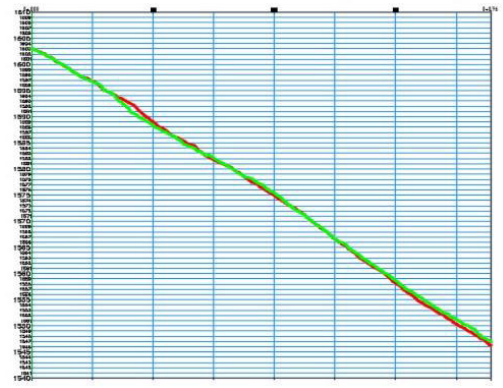

Fig. 11. Longitudinal section 1, where displacements are observed

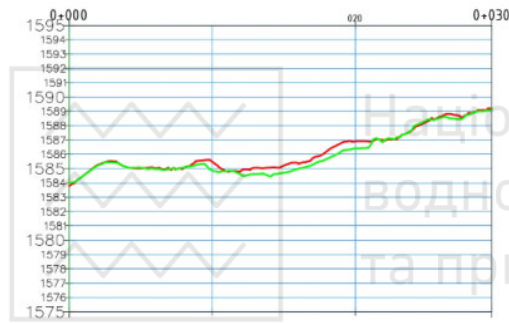

Fig. 13. Cross section $2-2$

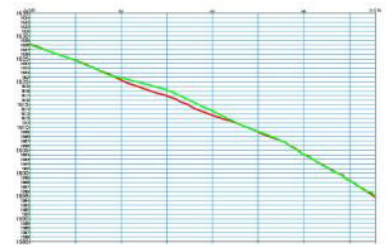

Fig. 15. Longitudinal section 2, where displacements are observed

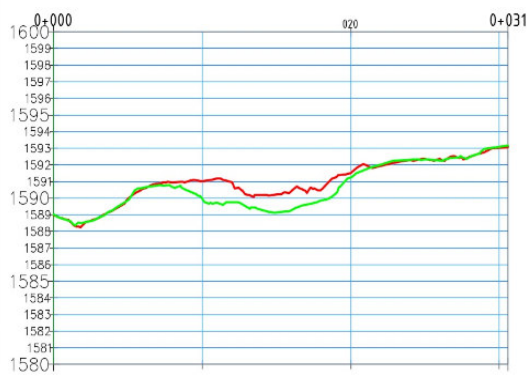

Fig. 12. Cross section 1-1

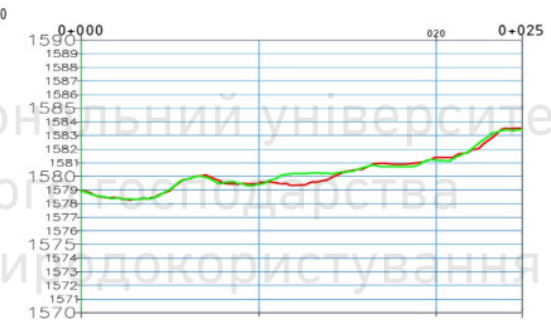

Fig. 14. Cross section 3-3

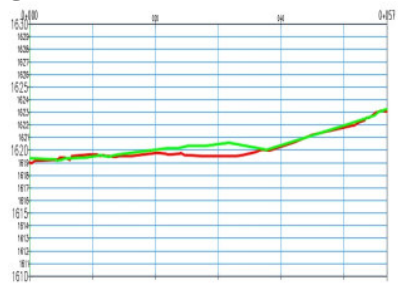

Fig. 16. Cross section 1-1

Поперечное сечение 2-2

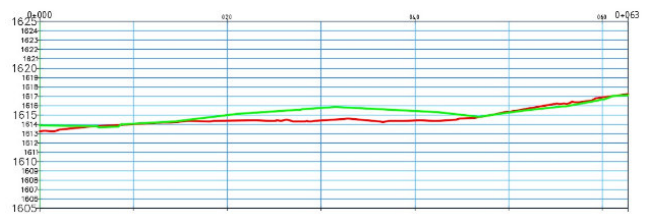

Fig. 17. Cross section 2-2 


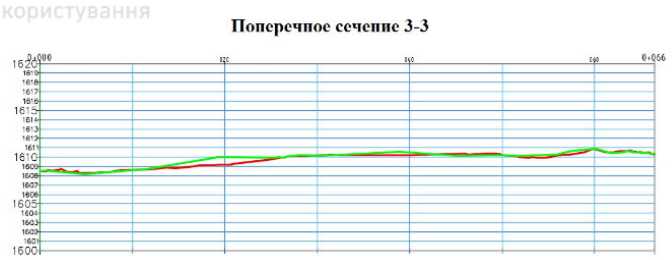

Fig. 18. Cross section 3-3

Such as the results of observations of deformation processes at the Kharanutskiy coal mine show that there no significant changes are observed on the sides and ledges of the section. Not any displacement massif mountain of a landslide nature is observed accordance to the results of the 2nd measurement cycle, however, talus was recorded in some parts of the section. Some changes recorded in the places of mining operations are due to the excavation of the rock mass and drilling and blasting operations. According to the deformation observations and side displacements of the Kharanutskiy coal mine, it can be concluded that at this stage not any critical displacements have been identified, despite of these places where small rockslides are manifested in the rock mass. Further observations are recommended.

The results of laser scanning confirm the drawn conclusions from the results of satellite observations at control points and the survey of the sides of the section. To perform work on ground-based laser scanning along the strike of the entire section, a special-purpose network (base stations, Fig. 19) was created with a high accuracy of mutual position in the WGS-84 coordinate system.

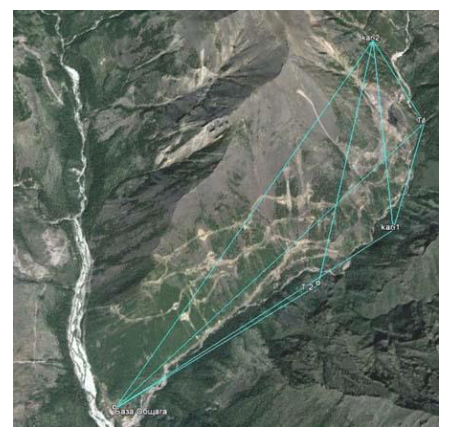

Fig. 19. Base station locations 
Conducting sequential series of laser scanning and the section GPS survey with the results subsequent analysis makes it possible to solve the following set of tasks: to carry out remote areal monitoring of the propagation of deformations of the sides with the identification of areas where surface subsidence occurs (landslide areas); determine the volumes of deforming masses; identify trends in the course of the deformation process; delineate hazardous areas; assign design sections to assess the stability of the pit walls; operational surveying accounting of the volume of mining operations performed.

\section{Approbation of the cycle of monitoring deformation processes on the example of a deep open pit}

When developing a methodology for observing the structures settlements, primary attention should be paid to justifying the accuracy and frequency of measurements. These issues are related to the adopted measurement scheme and the method of processing the measurement results, as well as the model for predicting deformations and depend on the initial indicators used in the calculation.

To calculate the accuracy of measurements, the formula can be used

$$
\sigma \Gamma=s_{0} \frac{\Delta}{6} s_{0} \frac{\delta}{3}, \quad \sigma_{\Gamma}=s_{0} \frac{\Delta}{6}=s_{0} \frac{\delta}{3}
$$

where $\sigma_{\Gamma}$ is the standard deviation of the measurement from a constant parameter, which is understood as the absolute and relative total values of the displacements;

$c_{0}-$ coefficient of transition from technologically normalized tolerance to the tolerance of its measurement;

$\Delta$ - technologically standardized tolerance;

$\delta$ - technologically permissible deviation.

Coefficient $\mathrm{c}_{0}$ varies within from 0,20 to 0,70 .

In cyclic measurements, the accuracy is normalized according to the formula

$$
\sigma \Gamma=\frac{\sigma \Gamma}{(n-1)}, \quad \sigma_{\Gamma_{\text {int }}}=\frac{\sigma}{(n-1)}
$$

that - standard deviation of parameter measurement in each tracking interval; 
$n$ - number of measurement cycles;

$(n-1)$ - tracking number intervals.

The main indicators when calculating the observations accuracy should be the values of the relative ultimate deformations. The observation accuracy calculation should be made based on the values that expected final limit values of settlements and deformations.

The surveying observations' accuracy that the structures deformations can be normalized based on the values where determine the limiting state of the altitude position of the structure under study and the nature of the flow of precipitation and deformation.

To ensure the structure stability, the settlement value obtained from the measurement results of the $(n+1)$ first cycle, and the absolute error of its determination must be less than the limiting value of the settlement, i.e.

$$
S_{t_{n+1}}+\delta_{S_{t_{n+1}}} \leq S
$$

the $\delta_{S t_{n+1}}$-is maximum error of the true draft value;

$S$ - design tolerance for the amount of draft.

The quantitative characteristic that serves to substantiate the method for measuring the settlement of structures, they are the marginal errors $\delta_{S t_{n+1}}$. Based on condition (3) and according to the amount settlement tolerance

$$
S_{i s t}+\delta_{S_{i s t}} \leq S,
$$

the $S_{i s t}$ - the benchmark (mark) settlement value equalized in the $(n+1)$ - first measurement cycle.

The deformations nature structures are determined, as known, by the magnitude and speed, i.e. change in the deformation process for the selected time interval. The accuracy and frequency of surveying measurements are prescribed in such a way that the results obtained satisfy the principle of practical confidence both in the magnitude of deformations at the time of observation and in its intensity, which allows, on the one hand, to judge the studied process invariability in time and the losing information impossibility about the nature of its change - on the other. So, the intensity value of deformations plays a more significant role than its absolute value. Following this, the 
measurements accuracy and frequency should be determined from the condition

$$
\Delta S=S\left(t_{i}\right)-S\left(t_{i-1}\right) \geq \sigma(\varepsilon),
$$

the $S\left(t_{i}\right)$ - is the amount of deformations at the time $t_{i}$;

$\sigma$ - standard deviation of strain determination;

$\varepsilon$ - coefficient depending on the measurement distribution errors and the level confidence.

The required measurement accuracy depends on the coefficient $\varepsilon$, for the determination of which it is necessary to have and a priori decision on the form of the distribution of measurement errors and the confidence probability, which characterizes the reliability of obtaining the desired values. The distribution law of measurement errors, as a rule, is close to normal, and the confidence probability is taken within the limits $0,955 \leq \beta \geq 0,977$. In this situation $\varepsilon$ varies in the range from 4.0 to 6.0 .

Depending on the measurement results responsibility, the optimal ratio between the assignment of the error and the expected deformation measurements result is determined. In practice, this ratio is taken to be from $1 / 4$ to $\square$. But for $\beta=0.995 \div 0.997$, the deformations will be within the confidence interval of the measurement errors. This means that the values taken for deformations may in fact turn out to be measurement errors. To avoid this, it is necessary to take a different relationship between the error and the expected result of strain measurement, for example, $1 / 4-1 / 6$, depending on the accepted confidence level.

The surveying observations accuracy of the structures deformations can be normalized based on the values that determine the altitude position's limiting state study structure and the precipitation and deformation flow nature.

Permissible errors in engineering structures determining settlement on various soils:

$0,001 \mathrm{~m}$ - for buildings and structures erected on rocky and semirocky soils;

$0,002 \mathrm{~m}$ - for buildings and structures erected on sandy and semisandy soils;

$0,005 \mathrm{~m}$ - for buildings and structures erected on bulk, subsidence, peat and other highly compressible soils. 
The measurement accuracy adopted in the first cycles, depending on the nature of the flow of precipitation, must be corrected. If " $n$ " measurement cycles have been made, then during calculating the accuracy in the $(n+1)$ - first cycle, the sediment equation obtained from the measurements results in the previous " $n$ " cycles is used.

The displacement rate of the points of the array is determined by the value of the displacement of the working benchmarks of the mine surveying observation station for a certain period of time in the direction of the displacement vector. Depending on the dynamics of the process, the rate of deformation can be measured: $\mathrm{m} /$ hour, $\mathrm{m} / \mathrm{day}$, $\mathrm{mm} /$ hour, $\mathrm{mm} /$ day, $\mathrm{mm} / \mathrm{month}$. To characterize the degree of danger of deformations, the most indicative is the displacement rate in the initial period of the active stage of the displacement and deformation process.

The latent stage of landslide development is the period at the beginning of the development of micromovements in the massif until the appearance of visible signs of the landslide formation of (the appearance cracks on the earth's surface, bulging of rocks at the base of the pit wall, and so on). The rate of displacement of the points of the array towards the end of the latent stage is $1-10 \mathrm{~mm} /$ day. The stage of landslide decay is the period of displacement of the landslide masses with a decreasing speed until the displacement completely stops. The timing of repeated observation cycles is set depending on the tasks set in the project and the development of the displacement process. According to the requirements of the instructions, in the first time after the laying of the observation station, observations are carried out monthly. After 3-4 series of observations and the establishment of the rate of displacement of the technogenic massif, the frequency of observations changes. If the rate of displacement of the benchmarks does not exceed $1 \mathrm{~mm}$ /day and decays in time, the time intervals between the series of observations can be increased to 3-4 or more months, but observations should be carried out at least 12 times a year. If the rate of displacement of the benchmarks is constant and is $0.5-1.0 \mathrm{~mm} /$ day, observations are carried out, respectively, once every two months and monthly. When the shift process is activated, the intervals between the series of observations are reduced to several weeks or even days. 
Methodological guidelines established that when observing active landslides with velocity displacements of $10 \mathrm{~mm} /$ day or more, a series of observations are carried out daily; if the rate of displacement of the benchmarks increases with time, then to establish the critical rate of displacement, preceding the failure of landslides, the time intervals between the series of observations are reduced to several hours, in some cases, automatic signaling devices of the rate of deformations are installed.

To calculate the speed of displacement of working benchmarks, use the formula

$$
v=\frac{S_{C P}}{T},
$$

the $S_{C P}$ - average displacement of working benchmarks over the observation period $t, \mathrm{~m}$.

so, the average value of the displacement is determined

$$
S_{c p}=\frac{S_{1} F_{1}+S_{2} F_{2}+\ldots S_{n} F_{n}}{F_{1}+F_{2}+\ldots+F_{n}},
$$

the $S_{1}, S_{2}, \ldots, S_{n}$ - benchmarks offset $1,2, \ldots, n, \mathrm{~m}$;

$F_{1}, F_{2}, \ldots, F_{n}$ - the area referred to the coverage area of the corresponding reference points. $\mathrm{m}^{2}$.

In some cases, the working benchmarks the average displacement's structure is calculated as the arithmetic mean of the sum of the absolute displacements of all benchmarks.

In accordance with the methodology of prof. N.G. Vidueva, the standard deviation of the draft is determined by the formula

$$
\sigma(v)=\frac{1}{\Delta t} \sqrt{\sigma^{2}(\Delta S)+v^{2} \sigma^{2}(\Delta t)}
$$

In this case, the relative error in determining the rate of settlement

will be

$$
\frac{\sigma(v)}{v}=\sqrt{\frac{\sigma^{2}(\Delta S)}{\Delta S^{2}}+\frac{\sigma^{2}(\Delta t)}{\Delta t^{2}}} .
$$

$f$ you set some value of the relative error $\frac{\sigma(v)}{v} \leq \frac{1}{N}$, then the standard deviations $\sigma(\Delta S)$ and $\sigma(\Delta t)$ must satisfy the condition 


$$
\frac{\sigma^{2}(\Delta S)}{\Delta S^{2}}+\frac{\sigma^{2}(\Delta t)}{\Delta t^{2}} \leq \frac{1}{N^{2}} .
$$

For a preliminary calculation, you can use the principle of equal influence of sources of errors, then

$$
\frac{\sigma(\Delta S)}{\Delta S}=\frac{\sigma(\Delta t)}{\Delta t}
$$

Here

$$
\frac{\sigma(\Delta t)}{\Delta t} \leq \frac{1}{N \sqrt{2}} .
$$

Having set some standard deviation, acceptable for specific observation conditions, $\sigma(\Delta t)$, we get

$$
\Delta t \geq N \sigma(\Delta t) \sqrt{2}
$$

the $\Delta t$ - the period during which precipitation changes evenly, day.

The required accuracy of such a period will be $\sigma(\Delta t) \leq \frac{\Delta t}{N \sqrt{2}}$.

Then we get

$$
\frac{\sigma(\Delta S)}{\Delta S} \leq \frac{1}{N \sqrt{2}} .
$$

Considering, that $\Delta S=v \Delta t$, can write

$$
\sigma(\Delta S) \leq \frac{v \Delta t}{N \sqrt{2}} .
$$

So, it becomes necessary to understand the rate of settlement [21]. When approximating the precipitation of one or another curve, an exponential curve is used, characterized by the equation

$$
S_{i}=S_{k}\left(1-e^{-\alpha t}\right) \text {. }
$$

the $S_{k}$ - final draft, m;

$\alpha$ - an empirical coefficient depending on the nature of the soil, foundation structure, load, etc.

The draft can be represented by another equation

$$
S_{\tau}=S_{k} \frac{t}{d+t}
$$

the $d$ - empirical coefficient $(0 \leq d \leq 1)$. 
The sediment values can also be approximated by a polynomial of the form

$$
S_{t i}=\sum_{i=1}^{p} a_{i} t^{i}
$$

Coefficient $\alpha$ fluctuates over a wide range $0.05<\alpha<2.5$.

When designing observations of the structure settlement, some parameter values that determine St are used, and in the process of observations, the model of settlement (the deformation process nature) is refined. For this model, the displacement rate of the working benchmarks is determined by the formula

$$
v=\frac{d S}{d t}=S_{k} \alpha \times e^{-\alpha t} .
$$

The rate of upsetting changes over time. For a certain period of time from $t_{1}$ to $t_{2}$, the offset reaches the value

$$
\Delta S=\int_{t_{1}}^{t_{2}} v \cdot d t=S_{k}\left(e^{-\alpha t_{1}}-e^{-\alpha t_{2}}\right) .
$$

Given some value of $t$, can find $\Delta t=t_{2}-t_{1}$ time interval at which the offset $\Delta S$ acquires a certain predetermined value. Determined $\Delta \mathrm{t}$ by solving the equation

$$
e^{-\alpha t_{2}}=e^{-\alpha t_{1}}-\frac{\Delta S}{S_{k}}=a,
$$

where

$$
t_{2}=-\frac{\ln a}{\alpha} \text {. }
$$

In this case $S_{k} \frac{\Delta S}{S_{k}}=\varepsilon=\mathrm{const}$

$$
e^{-\alpha t_{i}}=e^{-\alpha t_{i-1}} \varepsilon=a_{i}
$$

then

$$
t_{i}=-\frac{\ln a_{i}}{\alpha}
$$

The calculation of the required accuracy of determining the displacement of the benchmarks can be made using the absolute error of the displacement rate. Let us introduce the condition $\sigma(v) \leq \sigma_{0}(v)$. Then used the formula (8), we ger 


$$
\frac{1}{t} \sqrt{\sigma^{2}(\Delta S)+v^{2} \sigma^{2}(\Delta t)} \leq \sigma_{0}(v) .
$$

We will accept $\sigma^{2}(\Delta S)=v^{2} \sigma^{2}(\Delta t)$.

Then the accuracy of determining the observation period will be

$$
\sigma(\Delta t)=\frac{\sigma(\Delta S)}{v}
$$

This technique makes it possible not only to find the required accuracy of the precipitation measurement, but also to determine the observation period with an assessment of its accuracy.

When deciding on the rate of displacement of benchmarks, one proceeds from the absolute deformation critical for a given structure, which depends on the nature of the soil, foundation design, load, etc.

The degree of danger of deformations is determined from the rate of displacement and the magnitude of deformations by comparing them with the permissible deformations established for specific rocks, laboratory studies, and the deformation properties of rock samples.

At a steady rate of deformation (relative shear), the time to the collapse of the slope is determined from the expression

$$
\frac{y_{\text {Ip }}-y_{y \mathrm{II}}}{\mathrm{tg} \psi}=t
$$

the $\gamma_{p r}$ - the limiting relative shear deformation, established by laboratory tests of rocks or field observations, upon reaching which the destruction of the rock occurs;

$\gamma_{u s t}$ - shear deformation, upon reaching which a steady-state constant deformation rate is observed, $\mathrm{m}$;

$\psi$ - the slope of the segment of the dependence graph $\gamma=f(t)$ in the area of constant strain rate (the $\tan \varphi$ value numerically corresponds to the shear strain rate), degree.

Taking into account that the rate of shear deformation at the stage of decaying creep at any of its intervals is greater than the rate of deformation at the subsequent stage of steady-state creep, an approximate estimate of the time to destruction of the slope from the rate of deformation at the stage of decaying creep should be carried out by the expression 


\section{$t>\frac{y_{\text {mp }}-y_{i}}{\operatorname{tg} \psi_{i}^{\infty}}$,}

the $\gamma_{i}$ - shear deformation at the time of this calculation, $\mathrm{m}$;

$\operatorname{tg} \psi_{l}=v_{\gamma}$ shear strain rate at the decaying creep stage upon reaching the total shear $\gamma_{i}, \mathrm{~mm} /$ day.

When predicting the development of landslides of slopes of quarries and dumps in time, it is necessary to take into account, in addition to the increase in displacement rates, the development of a detachment crack outlining the landslide on the landslide flanks is also possible (the active stage of a landslide occurs when it is completely delineated by a separation crack on the flanks) According to the data of joint observations of the increase in the rates of displacement of the landslide in its central part and the development of separation cracks along the flanks of the landslide, the critical rates of displacement of the landslide are established for the given engineering-geological and mining conditions.

We will evaluate the accuracy of measurements with an electronic total station and a GPS system.

For deep quarries, it is characteristic that the length of the profile lines of the observation stations becomes significant, and the number of connecting benchmarks located on the near-belt strip and on the berms of the benches of a deep quarry also increases.

When observing the condition of the sides of deep quarries, it is necessary to substantiate the location of the reference, control and connecting benchmarks with an assessment of the accuracy of their planned-high-altitude position.

In accordance with the permissible errors in determining the planned and altitude position of the benchmarks, an assessment was made of the accuracy of the position of the tie benchmarks located on the side strip and on the berms of the benches of a deep pit.

The root-mean-square error of determining the excess by the trigonometric leveling method using an electronic total station is determined by the formula

$$
m_{h}^{2}=L^{2} \cos ^{2} \delta \frac{m_{\delta}^{2}}{\rho^{2}}+m_{L}^{2} \sin ^{2} \delta+2 m_{v}^{2}
$$


the $m_{\delta}, m_{L}, m_{V}$ - root mean square errors of measurement of the corresponding values (vertical angle, distance, instrument height and sighting).

The error in measuring distances with an electronic total station is determined by the expression $m_{L}=2 \mathrm{~mm} \pm 2 \mathrm{~mm} / \mathrm{km} L$, the $L$ - side length in km, UPC of vertical angle measurement for high-precision Leica TCR 1201 total station is 1.5".

The dependence of the root-mean-square error in determining the excess on the angle of inclination of the sighting beam of the telescope and the distance from the connecting reference to the working one is given in Table. 2

Table. 2

The root-mean-square error of determining the excess with three measurements with the Leica TCR 1201 total station

\begin{tabular}{c|c|c|c|c}
\hline \multirow{2}{*}{$\begin{array}{c}\text { Distance from } \\
\text { total station to } \\
\text { last benchmark } \\
L, \mathrm{~m}\end{array}$} & \multicolumn{4}{|c}{ Angle of inclination of the sighting axis, degree } \\
\cline { 2 - 5 } & \multicolumn{2}{|c|}{\begin{tabular}{c} 
Me5 \\
\cline { 2 - 4 }
\end{tabular}} & $\begin{array}{c}\text { Mean square error in determining the excess } \\
\text { measurement methods } m_{h}, \mathrm{~m}\end{array}$ \\
\hline 50 & 0,00085 & 0,00087 & 0,00090 & 0,00094 \\
\hline 100 & 0,00092 & 0,00094 & 0,00097 & 0,00101 \\
\hline 150 & 0,00104 & 0,00105 & 0,00107 & 0,00111 \\
\hline 200 & 0,00118 & 0,00119 & 0,00121 & 0,00123 \\
\hline 300 & 0,00150 & 0,00151 & 0,00152 & 0,00153 \\
\hline 400 & 0,00187 & 0,00187 & 0,00186 & 0,00186 \\
\hline 500 & 0,00225 & 0,00224 & 0,00223 & 0,00216 \\
\hline 600 & 0,00264 & 0,00263 & 0,00261 & 0,00258 \\
\hline 800 & 0,00345 & 0,00343 & 0,00339 & 0,00334 \\
\hline 1000 & 0,00427 & 0,00423 & 0,00418 & 0,00411 \\
\hline
\end{tabular}

The graph of the dependence of the measurement accuracy on the angle of inclination and the distance from the binder to the working benchmark is shown in Fig. 20. 


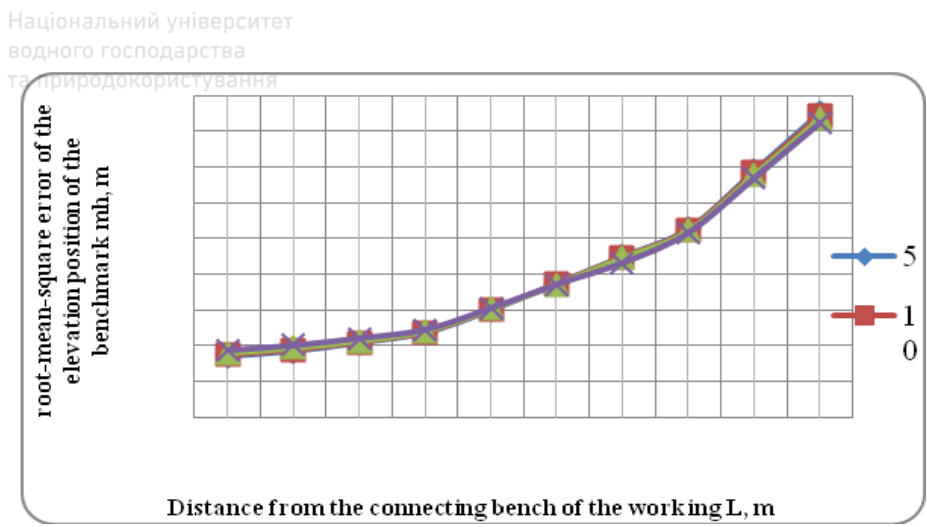

Fig. 20. measurement dependence graph of the accuracy on the angle of inclination and the distance from the working benchmark binder

The root-mean-square error of determining the position of the next linking reference will include the RMS of the first linking reference and the error of the actual method for determining the excess of the reference

$$
m_{(n+1)_{h}}^{2}=\sqrt{m_{(n)_{h}}^{2}+m_{h}^{2}}
$$

To calculate the accuracy, the angle of inclination of the sighting axis of $20^{\circ}$ was taken, which is most often found during instrumental observations along the profile lines on the side of the open pit.

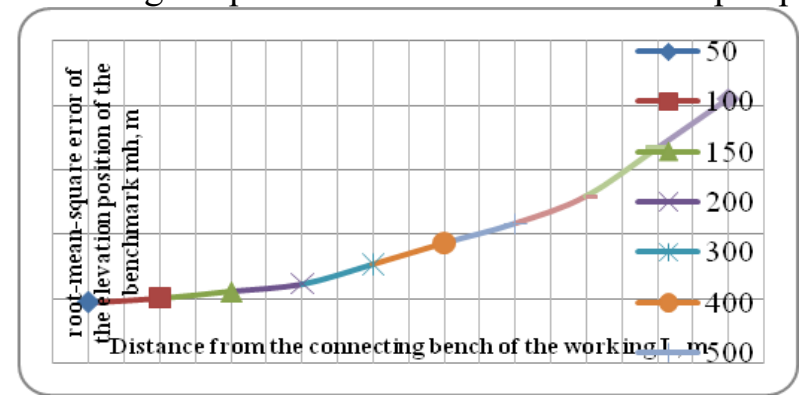

Fig. 21

The calculating results of the RMS determining the altitude position of the connecting benchmarks are summarized in Table 3 .

The root-mean-square determining error of the altitude position of the connecting benchmarks with three measurement techniques 
Table 3

\begin{tabular}{c|c|c|c|c|c|c}
\hline \multirow{2}{*}{$\begin{array}{l}\text { Binder } \\
\text { reference } \\
\text { number }\end{array}$} & \multicolumn{6}{|c}{ Distance between connecting benchmarks, $\mathrm{L} \mathrm{m}$} \\
\cline { 2 - 7 } & 100 & 200 & 300 & 400 & 500 & 600 \\
\cline { 2 - 7 } & \multicolumn{5}{|c}{ RMS for the height position of the tie marks, $\mathrm{m}_{\mathrm{h}} \mathrm{mm}$} \\
\hline 1 & 1,01 & 1,23 & 1,53 & 1,86 & 2,160 & 2,580 \\
\hline 2 & 1,43 & 1,739 & 2,164 & 2,630 & 3,055 & 3,649 \\
\hline 3 & 1,75 & 2,130 & 2,650 & 3,221 & 3,741 & 4,469 \\
\hline 4 & 2,02 & 2,460 & 3,060 & 3,719 & 4,320 & 5,160 \\
\hline
\end{tabular}

The graph of the change in the accuracy of determining the position of each next connecting benchmark is shown in Fig. 22.

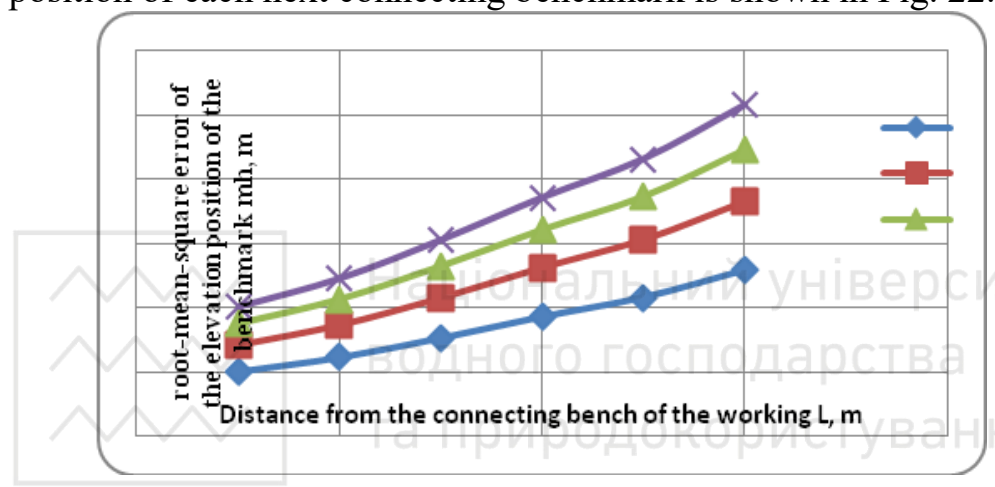

Fig. 22. Graph of changes in the accuracy of determining the position of each next linking reference

An analysis of instrumental measurements assessment accuracy determines the altitude position of tie marks shows that to ensure an admissible measurement error of $3 \mathrm{~mm}$, the number of tie points should be equal to $n=3$ at a distance between ties of $370 \mathrm{~m}$ and with three measurements with a high-precision Leica TCR 1201 total station.

The following main sources of errors affect the accuracy of determining the planned position of the connecting reference marks of stations using an electronic total station: - error of the proper method of polar coordinates $m_{\text {floor }}, \mathrm{m}$; - initial data $m_{I C X}, \mathrm{~m}$; centering the total station $m_{t s, t}, \mathrm{~m}$; - orientation of the original direction $m_{\text {orien }}, \mathrm{m}$; - fixing the reflector $m_{f . r}, \mathrm{~m}$. 
The average square error of determining the planned position of the first connecting reference point by the method of polar coordinates is determined by the expression

$$
m_{R}^{2}=m_{F L O O R}^{2}+m_{I S X}^{2}+m_{C . S}^{2}+m_{O R I E N}^{2}+m_{F . R}^{2}
$$

The average square error of the actual method of polar coordinates for " $n$ " measurement methods is determined by the formula

$$
m_{F L O O R}=\frac{1}{\sqrt{n}} \sqrt{m_{L}^{2}+\left(\frac{m_{\beta}}{r}\right) L^{2}}
$$

The error of orientation to the original direction is determined by the formula

$$
m_{\text {ORIENT }}=\frac{m_{\beta} L}{r}
$$

The results of the calculation of the UPC for determining the planned position of the connecting reference points at three measurement methods are summarized in Table 4.

Table 4

The average square error for determining the planned position of the connecting reference points at three measurement methods

\begin{tabular}{l|c|c|c|c|c|c}
\hline \multirow{2}{*}{$\begin{array}{l}\text { The } \\
\text { rapper's } \\
\text { binding } \\
\text { number }\end{array}$} & \multicolumn{5}{|c}{ Distance between connecting reference points, L m } \\
\cline { 2 - 7 } & 100 & 200 & 300 & 400 & 500 & 600 \\
\cline { 2 - 7 } & \multicolumn{7}{|c|}{$\begin{array}{c}\text { UPC of the planned position of the connecting reference points, } \mathrm{mR} \\
\mathrm{mm}\end{array}$} \\
\hline 1 & 2,120 & 2,396 & 2,764 & 30192 & 3,661 & 4,155 \\
\hline 2 & 2,487 & 2,824 & 3,255 & 3,749 & 4,285 & 4,848 \\
\hline 3 & 2,807 & 3,195 & 3,681 & 4,233 & 4,929 & 5,453 \\
\hline 4 & 3,094 & 3,527 & 4,063 & 4,667 & 5,318 & 5,998 \\
\hline
\end{tabular}

The analysis of the results of the measurement accuracy assessment showed that with three methods of measurement with the Leica TCR 1201 total station for determining the planned position of the reference points, the required accuracy of $3 \mathrm{~mm}$ is provided only for two connecting reference points located at a distance of $250 \mathrm{~m}$ from each other, which is insufficient for deep quarries. 
The results of the performed calculations of the UPC for determining the planned position of the connecting reference points with six measurement methods are summarized in Table 4.10.

Table 5

\begin{tabular}{c|c|c|c|c|c|c}
\hline \multirow{2}{*}{$\begin{array}{l}\text { The } \\
\text { rapper's } \\
\begin{array}{l}\text { binding } \\
\text { number }\end{array}\end{array}$} & \multicolumn{5}{|c}{ Distance between connecting reference points, L m } \\
\cline { 2 - 7 } & 100 & 200 & 300 & 400 & 500 & 600 \\
\cline { 2 - 7 } & \multicolumn{6}{c}{$\begin{array}{c}\text { UPC of the planned position of the connecting reference points, } \\
\mathrm{mR} \text { mm }\end{array}$} \\
\hline 1 & 1,910 & 2,150 & 2,482 & 2,874 & 3,305 & 3,761 \\
\hline 2 & 2,120 & 2,396 & 2,764 & 3,192 & 3,661 & 4,155 \\
\hline 3 & 2,311 & 2,619 & 3,020 & 3,482 & 3,985 & 4,515 \\
\hline 4 & 2,487 & 2,824 & 3,256 & 3,749 & 4,285 & 4,848 \\
\hline
\end{tabular}

The graph of changes in the accuracy of determining the position of each subsequent connecting reference point is shown in Fig.23.

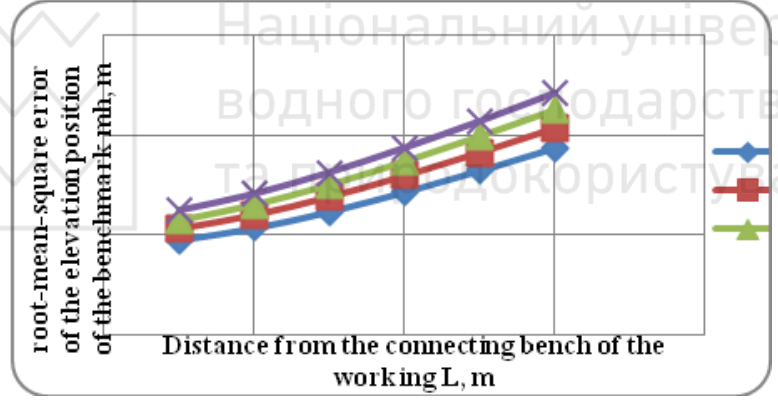

Fig. 23. Graph of changes in the accuracy of determining the position of each subsequent connecting reference point

For deep quarries with complex mining and geological conditions, a significant increase in the connecting reference points along the profile line of the observation station is characteristic. So, with an average distance between the connecting reference points equal to $300 \mathrm{~m}$, the average square error of the position of the connecting reference points according to calculations on the lower horizons is: the $1 \mathrm{st}$ binding reference point $3,2 \mathrm{~mm}$; the 2 nd binding reference point $3,5 \mathrm{~mm}$; the $3 \mathrm{rd}$ binding reference point $3,7 \mathrm{~mm}$; the 4th binding reference point $3.9 \mathrm{~mm}$. 
The accuracy analysis shows that the positions of the reference points obtained by the UPC exceed the permissible value of $3 \mathrm{~mm}$. Therefore, there is a need to improve the methods of production of instrumental observations by combining electronic total station and GPS observations.

After conducting studies of the accuracy of determining the planned altitude position of GPS reference points with GPS devices and taking into account the main factors that affect the accuracy of the work, you can express the UPC of the position with the following formula

$$
m_{\text {com-GPS }}=\sqrt{m_{c . p}^{2}+m_{T E C H N}^{2}+m_{G O R}^{2}+m_{T S . A}^{2}}
$$

the $m_{\text {ц.п- }}$ ошибка центрирования GPS приемника над связующим репером, мм;

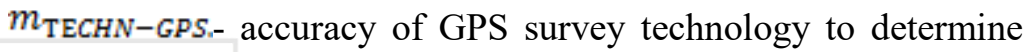
the position of points,

$m_{\mathrm{GOR}}$ - GPS receiver positioning error, $\mathrm{mm}$;

- error for instability of the antenna phase center, $\mathrm{mm}$.

The average square error of centering for the optical centering of the total station is determined by the formula, $\mathrm{mm}$

$$
n_{C . T}=e \sqrt{1+\left(\frac{L}{b}\right)^{2}}=0.5 \sqrt{2}=0,7
$$

the $e$ - the linear centering element, which is assumed to be equal to $0,5 \mathrm{~mm}$ and for $L \approx b, b$ - is the length of the basis.

The accuracy of the GPS survey technology depends on the technology and the measurement time. For connecting reference points of observation stations of deep quarries, the "fast static 20-30 minutes" technology is provided at a distance of $10 \mathrm{~km}$ from the base receiver, then $=1,0 \mathrm{~mm}$.

The horizontal error of the GPS receiver depends on the accuracy of setting the axis of the round level in the vertical position and is determined by the expression

$$
m_{G O R}=\frac{0.1 \tau}{r} h_{0}
$$

the $\tau$ - the price of dividing the round level of the reflector stand, seconds; 
$h_{0}-$ GPS receiver installation height, $\mathrm{m}$.

The GPS device has a round level, the division price of which is $10^{\prime}$ or $600 "$. Then the error of positioning the GPS receiver will be, $\mathrm{mm}$

$$
m_{G O R}=\frac{0.1 \times 600}{206265} 1500=0.44 .
$$

The error for the instability of the phase center of the antennas is taken on the basis of studies conducted in the "fast static" mode, which showed fluctuations of the phase center in the horizontal plane of less than $1.0 \mathrm{~mm}$.

The average square error of determining the planned position of the connecting reference point using GPS survey technology will be equal to, $\mathrm{mm}$

$$
\begin{gathered}
m_{\text {Comm3-GPS }}=\sqrt{m_{\text {e.p }}^{2}+m_{\text {Techn-GPS }}^{2}+m_{\text {gor. }}^{2}+m_{\text {eAd }}^{2}}= \\
\sqrt{0.7^{2}+1.0^{2}+0.44^{2}+1.0^{2}=1,64}
\end{gathered}
$$

The conducted studies proved the feasibility of using a GPS receiver to determine the planned altitude position of the connecting reference points for the combined method of instrumental observations, where the position of the working reference points of the observation stations will be determined by an electronic total station.

\section{Conclusion}

As a result of the practical implementation of complex geomechanical studies of the state of stability of instrument arrays of deep quarries on the basis of instrumental observations using advanced geodetic instruments and technologies, the following results were obtained:

1. Projects of observation stations for the state of stability of the sides have been developed in which, depending on the mining and geological conditions of field development, based on geomechanical studies of the composition and properties, structural and tectonic features of the instrument arrays of quarries, hydrogeological conditions of fields, assessment of the state of real slopes of deep quarries, the following are made: justification of the locations and structures of observation stations; choice of a method for systematic instrumental observations; the design of reference reference points, 
observation and control points of observation stations has been developed.

2. Two series of instrumental surveying and geodesic observations of the state of stability of the sides of quarries were performed using a robotic electronic total station TSA1201, GPS systems 1200, and a 3D scanner.

3. A complex method of geomechanical study of the stability state of deep quarry instrument arrays based on instrumental observations, spectral seismic and GPR profiling, laser scanning of the most dangerous areas of the quarry side is proposed, which allows us to most reliably justify the locations of observation stations based on the factor of tectonic (man-made) disturbance of the array, take into account the nature of rock deformation and predict their development in time and space.

4. A system of geomechanical monitoring of the stability state of the quarry instrument arrays has been designed, consisting of 17 observation stations ( 25 profile lines), including 972 reference points, 30 of them reference ones, which allows evaluating and predicting geomechanical processes occurring in the quarry instrument arrays and monitoring the correctness of decisions made on the parameters of the side slopes.

References

1. Seredovich, A.V. Application of three-dimensional laser scanning for determining the deformations of vertical reservoirs [Text] / A.V. Seredovich, A.V. Ivanov // Laser scanning and digital aerial photography. Today and tomorrow: tez. dokl. V-th International Conf. and exhibitions. - M.: XportMedia, 2005. - p. 43-46.

2. The method of calibration of ball tanks by ground-based laser scanning [Text] / A.V. Komissarov, M. S. Kalinina, E. A. Yegorchenkova, N. S. Korotchenko // Problems of collecting, preparing and transporting oil and petroleum products.2015. - №. 4 (102). - Pp. 163-170.

3. Agarkov I. B., Konovalov A.V. Estimation of displacements of ledges and sides of a quarry according to laser scanning data/ / https:/ /geomix.ru /blog/science lotsenka-smeshhenij-ustupov-i-bortov-karera.

4. S. V. Tursbekov, M. G. Aituganov. Fundamentals of creating a surveyor monitoring of the state of quarry instrument arrays// Bulletin of the KRSU. Karaganda,2013. - Volume 13. - No. 4. - p. 85-87.

5. Anikushkin M. N., Ground-based laser scanning systems. Experience of work Text. / M. N. Anikushkin/ / Geoprofi. 2005. - No. 1. - p. 49-50.

6. Yushkin V. F. Methods of three-dimensional modeling of rock massifs in the study of geomechanical properties and mining operations//INTEREXPO GEOSIBERIA.- Novosibirsk, 2015. - Siberian State University of Geosystems and Technologies.- Volume 2. - No. 3. - pp. 293-297. 
7. Laser scanner Z+F IMAGER 5006EX // https: / / www.gsi.ru /catalog /aser_scanner/zf_imager5006ex.

8. instruction for the production of surveying works/ Ministry of Coal Industry of the USSR. All-Union Research Institute of Mining Geomechanics and Surveying. - M.: Nedra, 1987240 p.

9. Leica TPS400 Series Easy, quick, reliable and powerful [Electronic resource]: Leica Geosystems website. Access mode: http://www.leicageosystems.com/common/shared/downloads/inc/downloader.asp?id=2226 LMSZ360 Laser mirror scanner. Technical documentation and users instructions. Horn: Riegl Laser measurement systems, 2003. 92 p.

10. Komissarov, A.V. Research on the accuracy of constructing a digital relief model based on ground-based laser scanning data [Text] / A.V. Komissarov// GEOSiberia-2006. Vol. 1. Geodesy, Афонин, Д.А. Геодезический контроль деформаций при строительстве городских подземных сооружений открытым способом: автореф. дис. ... канд. техн. наук: 25.00.32 / Афонин Дмитрий Андреевич. - СПб, 2013. - 22 с.

11. Afonin, D. A. Design of geometric parameters of ground-based laser scanning in the control of deformations of buildings and structures in conditions of dense development / D. A. Afonin, M. Ya. Bryn, E. G. Tolstov / / Geodesy and Cartography. 2013. - No. 2. - p. 2-7.

12. Bykov, A. B. The desired and the real in geometric modeling [Electronic resource] / A. B. Bykov// CAD and Graphics. - 2002. -№ 1. Access mode: http://www.sapr.ni/Archive/SG/2002/1/7/

13. Kanashin, H. B. Development of technology for ground-based scanning of railway stations: dis. ... kand. tehn. nauk: 25.00.35 / Kanashin Nikolay Vladimirovich. M., 2009. - 160 p.

14. Seredovich, A. B. Methodology for creating digital models of objects of . -2011.No2. -C. 96-99.

15. Seredovich, A. B. Application of the RISCAN PRO software product for registration of scans [Electronic resource] / A. B. Seredovich, A. B. Ivanov, O. A. Dementieva // Interexpo Geo-Siberia. - 2011. - №2. Access mode: http://cyberleninka.m/article/n/primenenie-programmnogo-produkta-riscan-pro-dlyaregistratsii-skanov.

16. Autodesc information site:http:/www.autodesk.com/products/recap/ overview.

17. Vinogradov, K. P. Perspective methods of processing the results of ground-based laser scanning/ K. P. Vinogradov / / Vestnik. Architect. 21st century. - 2011. - №2 (39).C.80-81.

18. Autodesk AutoCAD Civil 3D/https://cad.EN/ support/bz/ archive / 82/ autodeskautocad-civil-3d.

19. Software Rimining mining for laser scanner RIEGL VZ series/ www.riegl.ru.

20. Manual deformation of the sides of the slopes of the ledges and dumps in quarries and the development of measures to ensure their sustainability" (UTV. Gosgortekhnadzor of the USSR 21.07.1970)

21. Methodological guidelines for monitoring deformations of sides, slopes of ledges and dumps in quarries and developing measures to ensure their stability/Approved by Order 
No. 39 of the Committee for State Control over Emergency Situations and Industrial Safety of the Republic of Kazakhstan dated September 22, 2008.

https://doi.org/10.31713/m1015

\section{THEORY AND PRACTICE OF DETERMINING THE CATEGORY HAZARD OF COAL MINES BY THE GAS FACTOR}

E. Filatieva
Volodymyr Dahl East Ukrainian National University, Senior
Lecturer, Ukraine

A. Oleinichenko

Volodymyr Dahl East Ukrainian National University, Senior Lecturer, Ukraine

M. Filatiev
$\begin{aligned} & \text { Volodymyr Dahl East Ukrainian National University, Doctor } \\ & \text { of Engineering Sciences, Associate Professor, Ukraine } \\ & \text { V. Sokolenko }\end{aligned}$
Volodymyr Dahl East Ukrainian National University, Candidate of
technical science, Associate Professor, Ukraine

\section{Annotation}

A comparative analysis of the theoretical and practical definition of the category hazard of coal mines by gas factor based on experimental data obtained in real conditions of mining gas-bearing coal seams is presented. The mine's hazard category by gas factor is determined in accordance with the current regulatory document. The processing of experimental data obtained in field studies leads to contradictions in the requirements for the safe mining of gas-bearing coal seams. The necessity of changing the regulatory framework for predicting methane release and establishing the category hazard of mines by gas factor is substantiated, as well as the theoretical part of the research is experimentally confirmed and practical proposals are given to improve the requirements of regulatory documents for the safe mining of gas-bearing coal seams.

The gas release from seven possible sources, the exposed surface of the working face, the undermined adjacent seams and their enclosing rocks, the overworked adjacent seams and enclosing rocks, the worked-out space of the stopped lavas, are accepted for consideration. The studies have shown that by removal the bottom from cut and the area of the mined-out space of the operated section and the wing of the 